\title{
A Study of Hybrid Energy Storage System for Electric vehicle Air Conditioning System
}

\author{
Phucha Veerathanaporn ${ }^{1, *}$, Danai Phaoharuhansa ${ }^{1}$, and Masaki Yamakita ${ }^{2}$ \\ 1Department of Mechanical Engineering, King Mongkut's University of Technology Thonburi, Bangkok, Thailand \\ ${ }^{2}$ Department of Mechanical and Control Systems Engineering, Tokyo Institute of Technology, Japan
}

\begin{abstract}
This paper introduces improvement efficiency of battery for air-conditioning (A/C) system. Super-capacitor (SCs) is mounted with Lithium-ion battery called hybrid energy storage system (HESS). The system modeling of heat system in passenger room and battery pack are derived to represent system in mathematic model. The characteristic of power loss relative to discharge rate are examined using several models of Li-Ion battery. The relationship between discharge rate and power loss in battery is tested by experiment kits. A/C system of passenger car is simplified to demonstration kit. Single energy storage system (SESS) and HESS batteries are used as energy storage. The both typed of energy storage are tested with on-off control. HESS outperforms rather than SESS. The efficiency of HESS battery is greater than SESS about $57.57 \%$ at peak load and $14.34 \%$ at rated load.
\end{abstract}

\section{Introduction}

Nowadays, the pollution problem is increasing which causes global warming, so the amount of electric vehicle (EV) are increasing to reduces the pollution problem [1]. Lithium-ion (Li-Ion) battery pack is usually used in commercial EV. The single type of battery cell is wellknown as single energy storage system (SESS). Energy consumption of EV is consumed by two main systems such as powertrain system and air-conditioning system $(\mathrm{A} / \mathrm{C}) . \mathrm{A} / \mathrm{C}$ system is an essential system of electric vehicle for driver's comfort.

The papers [2-4] has introduced that peak load was occurred when $\mathrm{A} / \mathrm{C}$ system and powertrain system are enabled at the same time. Energy consumption of $\mathrm{A} / \mathrm{C}$ system decreases driving range about 36\% [2]. Discharge efficiency will be reduced when discharge current is greater than $1 \mathrm{C}$-rate or high fluctuation [5]. The peak load of battery pack is main cause which reduce the efficiency of energy consumption in $\mathrm{A} / \mathrm{C}$ system.

There are many types of controller for automotive A/C system such as on-off controller, PID controller and Fuzzy controller. On-off controller is usually used for conventional automotive

Fig. 1 presents the diagram of on-off control system. The temperature in passenger room (Ti) is feedback to the on-off controller by temperature sensor. On-off controller will compare with desired temperature (Td) . Then, it will perform $\mathrm{A} / \mathrm{C}$ system, if temperature in passenger is higher than desired temperature.

Hybrid energy storage system (HESS) consist of different kind of battery types. Super-capacitor (SCs) is mounted with conventional battery such as lead-acid or
Li-Ion. Supercapacitor obtains discharge rat greater than others battery types so that it can reduce the peak current of battery pack. They have many advantages such as large discharge current in short time, low internal resistance, wide range operation temperature, and longlife cycle time. Moreover, the supercapacitor has significant effect to reducing temperature of battery and extend battery lifespan [6-7]. Thus, supercapacitor is one of device to improve discharge current and efficiency of battery.

Therefore, this research will introduce heat balanced of automotive $\mathrm{A} / \mathrm{C}$ system, characteristic of battery pack and improvement of efficiency and power loss of battery at peak. on-off control system is used to demonstrate energy consumption of SESS and HESS.

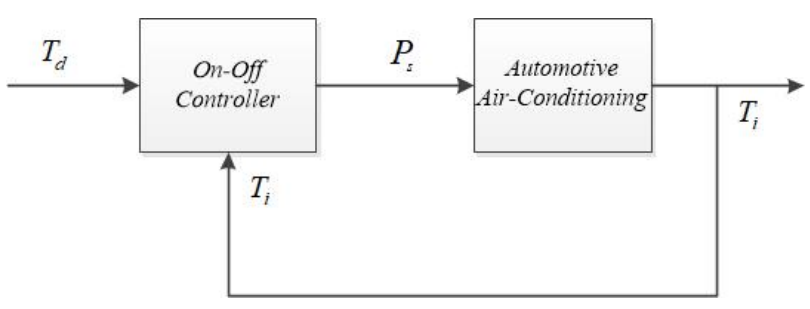

Fig. 1. Schematic diagram of on-off control system.

\section{System modeling development}

Air-condition load is considered to derive the mathematical model of passenger room. Load of $\mathrm{A} / \mathrm{C}$ system consists of battery temperature, solar radiation, metabolic and ambient temperature. The models will be presented as follows

*Corresponding author: phucha.v@mail.kmutt.ac.th 


\subsection{Passenger model}

Passenger model describes the relationship between total heat input $\left(\sum \dot{Q}_{i p}\right)$, heat output $\left(\dot{Q}_{o p}\right)$, and the variation heat in passenger room $\left(\dot{Q}_{p}\right)$. The equation is given as

$$
\dot{Q}_{p}=\sum \dot{Q}_{i p}-\dot{Q}_{o p}
$$

Total heat input is calculated by summation of heat flow from battery pack $\left(\dot{Q}_{b p}\right)$, solar $\left(\dot{Q}_{s p}\right)$, and metabolic $\left(\dot{Q}_{m p}\right)$. It is expressed that

$$
\dot{Q}_{i p}=\dot{Q}_{b p}+\dot{Q}_{s p}+\dot{Q}_{m p}
$$

Heat transfer between battery pack and passenger room is occurred when temperature of battery pack $\left(T_{b}\right)$ and passenger room $\left(T_{i}\right)$ are different level. It is written as

$$
\dot{Q}_{b p}=U_{p} A_{b p}\left(T_{b}-T_{i}\right)
$$

where, $U_{p}$ is overall heat transfer coefficient between battery pack and passenger room. $A_{b p}$ is area on top surface of battery pack. $T_{b}$ is temperature of battery pack. $T_{i}$ is temperature in passenger room.

The heat radiation from solar to passenger room is expressed as Eq.(4). An average of solar irradiation $\left(\dot{Q}_{s i}\right)$ in Thailand is approximately about $1000 \mathrm{~W} / \mathrm{m}^{2}$. The heat radiation enters to the passenger room pass though the surface such as roof and windshield. Which depends on heat transfer area and absorptivity of material.

$$
\dot{Q}_{s p}=\dot{Q}_{s i}\left(A_{r} \beta_{r}+A_{g} \beta_{g}\right)
$$

where, $A_{r}$ is area of roof. $A_{g}$ is area of windshield. $\beta_{r}$ is absorptivity of roof. $\beta_{g}$ is absorptivity of glass.

When the driver or passenger is inside the vehicle, the heat is generated by metabolism from body. The heat from metabolic is given as

$$
\dot{Q}_{m p}=\sum_{\text {passenger }} M_{m} A
$$

where, $M_{m}$ is constant of passenger metabolic heat. $A$ is constant, which estimate from body. It depends on weight and height.

The heat output of the system is occurred from the air-conditioning system. The equation is written as

$$
\dot{Q}_{o p}=\eta_{C O P} P_{s}
$$

where, $\eta_{C O P}$ is coefficient of performance of electric compressor in $\mathrm{A} / \mathrm{C}$ system. $P_{s}$ denotes power of air conditioning system, which equals with discharge power from battery pack

As above sentences, the equation of passenger model can be derived to equation as show in Eq. (7)

$$
\dot{T}_{i}=\left(\frac{\dot{Q}_{s p}+\dot{Q}_{m p}-\left(\eta_{C O P} P_{s}\right)}{m_{a} c_{p a}}\right)
$$

where, $m_{a}$ is mass of air. $c_{p a}$ is specific heat of air

\section{Experiment on battery efficiency}

The efficiency of battery is usually related to discharge current when the discharge current of battery increases, the battery capacities is decreased more than discharge energy because the power loss has been occurred as in battery.

Experiment is configured as shown in Fig. 2, it consists of 5 main components: motor, speed controller, battery pack, receiver, and remote controller. The motor is load of the system, which is adjusted sped of motor by controller.

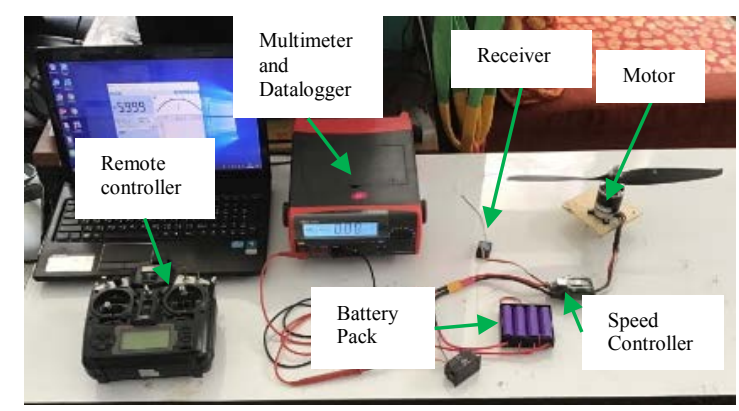

Fig. 2. Demonstration kit for efficiency of battery.

The battery models in this experiment are LG M26, LG HG2 and LG MH1 which have capacities such as 2,600 mAh, 3,000 mAh, and 3,200 mAh, respectively. The cells are packed as 4-series and 1-parallel (4S1P) which obtain energy is $38.48,44.4$, and $47.36 \mathrm{Wh}$, respectively. The battery pack is discharged at constant discharge current in each discharge rate until the ESC stop supplying power supply from battery with $\mathrm{A} / \mathrm{C}$ system. The result of discharge current, efficiency, and the coefficient of power loss are shown in Table 1. The coefficient of power loss is calculated by equation which express as

$$
C_{p}=\frac{1-\eta}{n_{p}}
$$

where, $C_{p}$ is coefficient of power loss, $\eta$ is efficiency of battery. $n_{p}$ denotes number of parallel can be found from specification of battery in Table 2 .

Table 2. Efficiency of 18650 Li-Ion battery at several discharge current.

\begin{tabular}{|c|c|c|c|c|}
\hline Battery model & $\begin{array}{c}\text { Discharge } \\
\text { Rate [A] }\end{array}$ & $\begin{array}{c}\text { Discharge } \\
\text { Current [A] }\end{array}$ & $\eta$ & \multirow{2}{*}{$C_{p}$} \\
\hline \multirow{3}{*}{ LG M26 2.6Ah } & 1.0 & 0.94 & 1.10 & \multirow{3}{*}{0.024} \\
\cline { 2 - 4 } & 2.6 & 2.41 & 0.81 & \\
\cline { 2 - 4 } & 5.0 & 4.98 & 0.51 & \\
\hline \multirow{3}{*}{ LG HG2 3Ah } & 1.0 & 0.93 & 0.72 & \multirow{3}{*}{0.029} \\
\cline { 2 - 4 } & 3.0 & 3.02 & 0.71 & \\
\cline { 2 - 4 } & 5.0 & 4.80 & 0.54 & \\
\hline LG MH1 3.2Ah & 1.0 & 0.99 & 0.70 & 0.026 \\
\hline
\end{tabular}




\begin{tabular}{|c|c|c|c|c|}
\hline Battery model & $\begin{array}{c}\text { Discharge } \\
\text { Rate [A] }\end{array}$ & $\begin{array}{c}\text { Discharge } \\
\text { Current [A] }\end{array}$ & $\eta$ & $C_{p}$ \\
\hline & 3.2 & 2.85 & 0.65 & \\
\cline { 2 - 4 } & 5.0 & 5.07 & 0.47 & \\
\hline
\end{tabular}

Table 3. Specification of batteries and supercapacitor.

\begin{tabular}{|l|c|c|c|c|}
\hline & LG M26 & LG HG2 & LG MH1 & SCs \\
\hline Maximum capacity (Ah) & 2.6 & 3 & 3.2 & - \\
\hline $\begin{array}{l}\text { Fully charged voltage } \\
(\mathrm{V})\end{array}$ & 4.2 & 4.2 & 4.2 & 2.85 \\
\hline Energy maximum (Wh) & 10.92 & 12.6 & 13.44 & 0.1 \\
\hline Rated Capacitance (F) & - & - & - & 100 \\
\hline $\begin{array}{l}\text { Maximum continuous } \\
\text { discharge current (A) }\end{array}$ & 10 & 20 & 10 & - \\
\hline $\begin{array}{l}\text { Nominal battery and SCs } \\
\text { discharge current }(\mathrm{A})\end{array}$ & 2.2 & 2.5 & 2.7 & - \\
\hline Internal resistance $(\Omega)$ & 0.060 & 0.017 & 0.007 & 0.012 \\
\hline $\begin{array}{l}\text { Capacity (Ah) at nominal } \\
\text { voltage }\end{array}$ & 2.2 & 2.5 & 2.8 & - \\
\hline Nominal voltage $(\mathrm{V})$ & 3.65 & 3.6 & 3.7 & 2.7 \\
\hline Rated capacity $(\mathrm{Ah})$ & 2.6 & 3 & 3.2 & - \\
\hline Number of parallel $\left(n_{p}\right)$ & 22 & 19 & 18 & - \\
\hline
\end{tabular}

According to the experiment result, the power had not supplied to the motor before the voltage of battery emptied because the current control was not permitting to discharge current. The cause of discharge permission is insufficient supply power from battery to meet power requirement of motor

The result presents efficiency and power loss of battery relative to discharge rate as shown in Fig. 3 and Fig. 4. The efficiency of battery decreases when discharge current enlarges. It affects an amount of power loss. The efficiency of batteries can be presented relative to discharge current as follow;

$$
\begin{aligned}
& \eta_{d i s, \text { bat }, L G M 26}=\left(-0.14 \cdot I_{d i s, L G M 26}\right)+1.21 \\
& \eta_{d i s, b a t, L G H G 2}=\left(-0.05 \cdot I_{d i s, L G H G 2}\right)+0.78 \\
& \eta_{d i s \text { batt }, L G M H 1}=\left(-0.04 \cdot I_{d i s, L G M H 1}\right)+0.79
\end{aligned}
$$

where, $\eta_{\text {dis.batt }}$ is efficiency of batteries. $I_{\text {dis }}$ is discharge current of batteries. The relationships between power loss with power supply are calculated by the equations, which are expressed as

$$
\begin{aligned}
& P_{l, L G M 26}=\left(0.024 \cdot P_{s, L G M 26}\right)+5 e^{-05} \\
& P_{l, L G H G 2}=\left(0.028 \cdot P_{s, L G H G 2}\right)-3 e^{-05} \\
& P_{l, L G M H 1}=\left(0.026 \cdot P_{s, L G M H 1}\right)-3 e^{-05}
\end{aligned}
$$

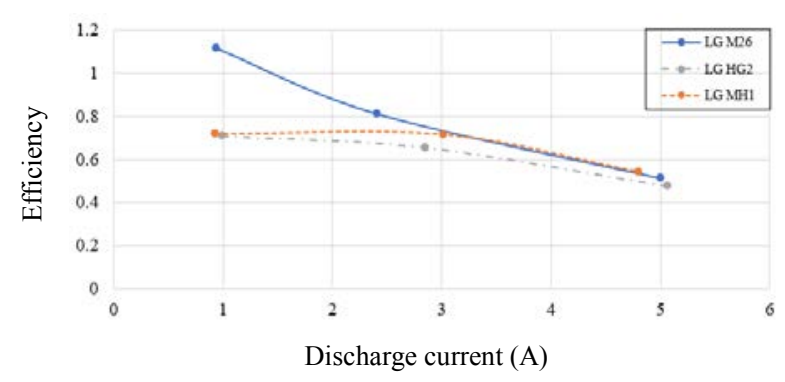

Fig. 3. Efficiency with discharge current of Li-Ion battery.

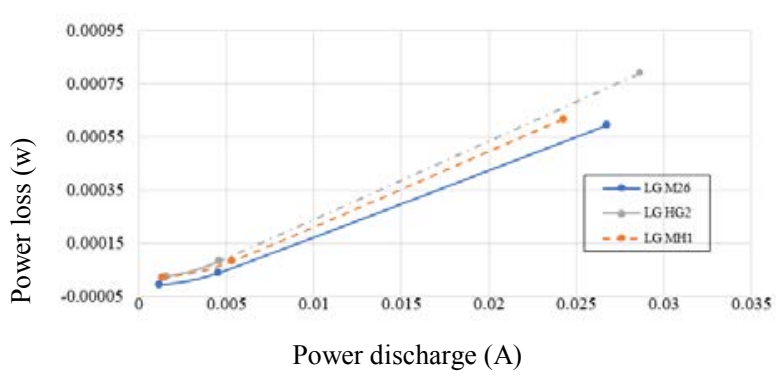

Fig. 4. Power loss with power discharge of Li-Ion battery.

\section{Experiment of energy consumption}

This topic presents experiment of single energy storage system (SESS) and hybrid energy storage system (HESS) to control temperature in control room. 4S1P LG M26 is used as SESS. HESS consist of 4S1P LG M26 and SCs. The super-capacitor is mounted with SESS as parallel. The energy of battery pack is $38.48 \mathrm{Wh}$ and SCs is 0.55 Wh. This experiment is designed to find efficiency of HESS that affect to $\mathrm{A} / \mathrm{C}$ system.

To simplify passenger model in Eq. (7) which neglect the heat of battery pack, the ratio of heat energy output with input passenger model is 2.49. Fig.5 illustrates block diagram of energy consumption experiment. It consists of energy storage, on-off control system and A/C system. The Eq. (7) is represented for experiment system that $\dot{Q}_{i a}$ of control room is 7 watts, $\dot{Q}_{s p}$ and $\dot{Q}_{m p}$ are replaced by heat input from heater which is defined as 12.45 watts, and the heat output of demonstration kit $\left(\dot{Q}_{o}\right)$ is 48.2 watts. Then, Eq. (7) is transform as follow;

$$
\left(\dot{Q}_{h}+\dot{Q}_{i a}\right)-\dot{Q}_{o}=m_{a / c} c_{p, a / c} \dot{T}_{i, a / c}
$$

where, $\dot{Q}_{h}$ is the heat energy input which consist of $\dot{Q}_{s p} \quad$ and $\dot{Q}_{m p} \cdot \dot{Q}_{i a}$ is the heat energy input from ambient. $\dot{Q}_{o}$ is the heat energy output by demonstration A/C system. $m_{a / c}$ is mass of air in control room. $c_{p, a / c}$ is specific heat of air in control room. $\dot{T}_{i, a / c}$ is changing temperature in control room.

Battery and supercapacitor are connected in parallel. When $\mathrm{A} / \mathrm{C}$ system turn on, battery and supercapacitor discharge current collaboratively to electronic speed control (ESC). Then, when $\mathrm{A} / \mathrm{C}$ system turn off, supercapacitor will be recharged by battery. 


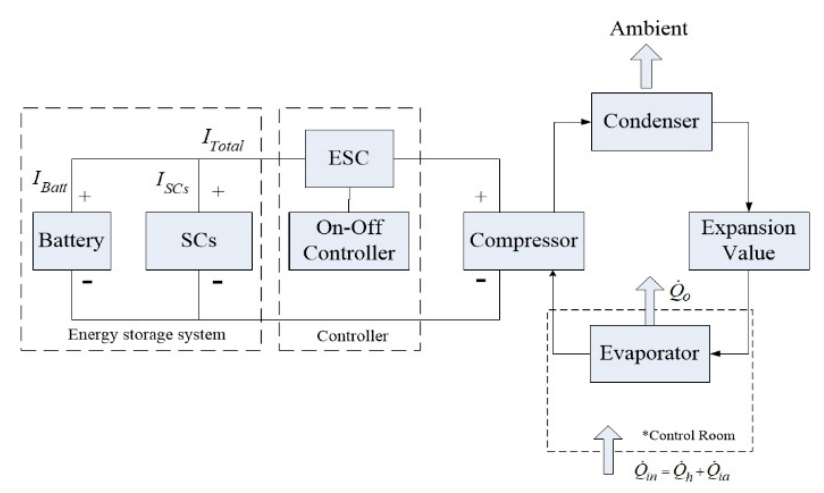

Fig. 5. Block diagram of demonstration kit.

\section{Result}

The results present variation of temperature in control room using SESS and HESS, energy consumption using SESS and HESS, the efficiency of battery using SESS and HESS at peak, power loss using SESS and HESS at peak. The boundary condition is defined that the desired temperature $\left(T_{d}\right)$ is $25 \pm 1{ }^{\circ} \mathrm{C}$, initial temperature $\left(T_{i n t}\right)$ is $30^{\circ} \mathrm{C}$, and ambient temperature $\left(T_{a}\right)$ is $26^{\circ} \mathrm{C}$. The on-off control is bases on Hysteresis control system. If temperature is higher than $26^{\circ} \mathrm{C}$, the $\mathrm{A} / \mathrm{C}$ system turn on. On the other hand, if temperature is lower than $24^{\circ} \mathrm{C}$, the $\mathrm{A} / \mathrm{C}$ system turn off.

Temperature in control room using SESS and HESS is shown in Fig. 6. The temperature in control room using SESS and HESS achieve the desired temperature about 549 second and 367 second, respectively. Thus, using SESS achieve desired temperature slower than using HESS about $31.28 \%$.

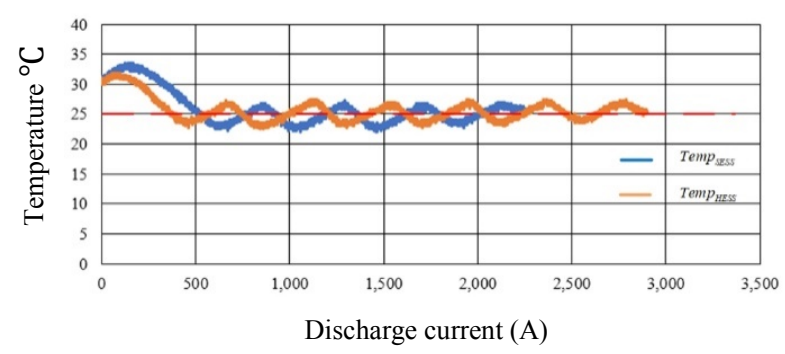

Fig. 6. Variation of temperature in control room using SESS and HESS

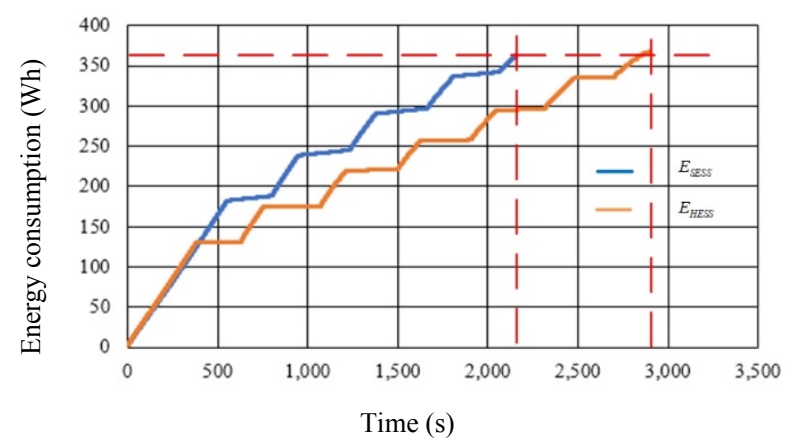

Fig. 7. Energy consumption of SESS and HESS.

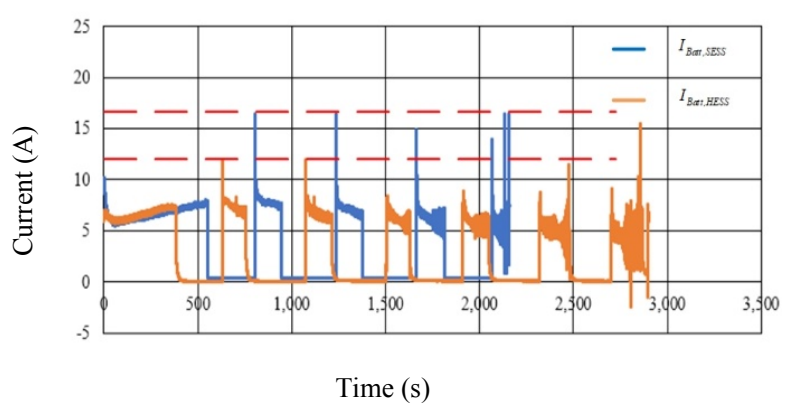

a) Comparison discharge current of Li-Ion in SESS and HESS

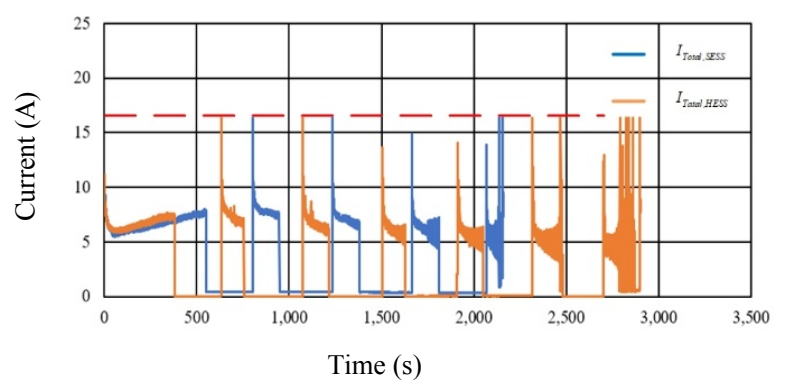

b) Total discharge current of SESS and HESS to A/C system.

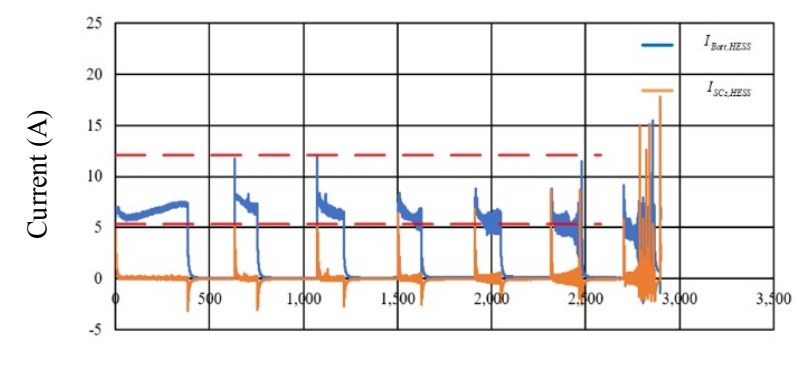

Time (s)

c) Discharge current of Li-Ion in HESS and discharge current of SCs in HESS to A/C system.

Fig. 8. Discharge current of single energy storage system (SESS) and hybrid energy storage system (HESS).

The energy consumption of SESS and HESS is not much difference because the air-conditoing system using SESS and HESS is stop suppling power at $22.7 \%$ of SOC battery. SOC is calculated in Eq. (16). The operation period of control temperature using HESS and SESS are 2900 and 2253 second, respectively. Thus, the operation period of HESS is longer than SESS about $22.3 \%$ of SESS as shown in Fig. 7.

Fig. 8 presents the discharge current using single energy storage system (SESS) and hybrid energy storage system (HESS) during temperature control at $25 \pm 1{ }^{\circ} \mathrm{C}$. The result of peak load and rated load are considered. The peak load will occur while electric compressor is starting, and rated load will occur while electric compressor consumes stable power consumption. The peak load will occur, while electric compressor is starting, the load will surge high discharge current. After electronic compressor is starting, the current will decrease nearly to constant which it is called rated load.

The discharge current of Li-Ion battery pack in SESS and HESS to A/C system are compared as show in Fig. 8a. At peak load, the discharge current is $16.38 \mathrm{~A}$ and $11.78 \mathrm{~A}$, respectively. Thus, the discharge current battery of HESS can be decreased about $28.07 \%$. 
Fig. 8b presents total discharge current between SESS and HESS. The total discharge current at peak load and rated load are not much different. However, the total discharge current at starting $\mathrm{A} / \mathrm{C}$ system of SESS and HESS are 9.57A and 10.735A, respectively, which increase about $10.85 \%$.

Fig. 8c presents discharge current of HESS between Li-Ion and SCs. At peak load, the discharge current of Li-Ion and SCs are 11.98A and 4.68A, respectively. At rated load, the Li-Ion battery still discharge current about 6.49A to A/C while SCs can't discharge current. Moreover, the SCs is recharged by battery in short time when $\mathrm{A} / \mathrm{C}$ system turn off.

The efficiency of battery at peak load and rated load is calculated by Eq. (9). The efficiency of HESS battery is greater than SESS about $57.57 \%$ at peak load and $14.34 \%$ at rated load.

The power discharge of battery can be derived using Eq. (12) thtat the power discharge of Li-Ion battery at peak load of SESS and HESS are 198.88 watts and 160.30 watts, respectivly. The power discharge of HESS is lower than SESS about $19.36 \%$. Moreover, the power loss of HESS is improved about $16.59 \%$ comparison with SESS.

\section{Conclusion}

This paper develops improvement of the efficiency and power loss in Li-Ion battery. The characteristic of Li-Ion batteries such as efficiency and power loss are related with discharge current. LGM26, LGHG2, LGMH1 models are tested and LGM26 model outperforms than other batteries. Single energy storage system (SESS) contains only LGM26 Li-Ion battery and hybrid energy storage system (HESS) consists of LGM26 Li-Ion battery and super-capacitor (SCs).

The temperature in control room using HESS achieves the desired temperature faster than SESS about $31.28 \%$ because SCs supplies additional current to A/C system. The total discharge current of HESS is higher than SESS during beginning period, but the total current is slightly lower than SESS during another period.

The efficiency and power loss at peak of Li-Ion battery in HESS is better than SESS about $57.57 \%$ and $16.59 \%$ because SCs can reduced the discharge current as shown in Fig. 8a. The fluctuation of HESS has high amplitude than SESS.
Especially, SOC of batteries become low. The fluctuation also become higher than the previous because the battery in HESS isn't supplied to A/C system but also super-capacitor.

The HESS outperforms rather than SESS. The SCs can reduce with surge current at peak load which occur frequently in on-off control system.

\section{References}

1. Yong Li, Jie Yang, and Jian Song, Design structure model and renewable energy technology for rechargeable battery towards greener and more sustainable electric vehicle, Renewable and Sustainable Energy Reviews, vol. 74, pp. 19-25, (2018).

2. R. Farrington and J. Rugh, Impact of Vehicle AirConditioning on Fuel Economy, Tailpipe Emissions, and Electric Vehicle Range, the Earth Technologies Forum, (2000).

3. Ziqi Zhang, Dandong Wang, Chenquan Zhang, and Jiangping Chen, Electric vehicle range extension strategies based on improved AC system in cold climate, International Journal of Refrigeration, vol. 88, pp. 141-150, (2018).

4. Brahim Mebarki, Boumediene Allaoua, Draoui Belkacem, Elhadj Benachour, and Lakhdar Rahmani, Impact of Air-Conditioning System on the Power Consumption of an Electric Vehicle Powered by Lithium-Ion Battery, Modelling and Simulation in Engineering, vol. 2013, (2013).

5. Chelladurai A/L Sinkaram, Vijanth S. Asirvadam, Nursyarizal Bin Mohd Nor, and Mumtaj Begam, Battery characteristics due to various discharging current and temperatures: A simulation approach, IEEE Student Conference on Research and Development (SCOReD), (2012).

6. Rebecca Carter, Andrew Cruden, and Peter J. Hall, Optimizing for Efficiency or Battery Life in a Battery/Supercapacitor Electric Vehicle, IEEE Transactions on Vehicular Technology, vol. 61, (2012).

7. S. Pay, and Y. Baghzouz, Effectiveness of batterysupercapacitor combination in electric vehicles, IEEE Bologna Power Tech Conference Proceedings, (2003). 